\title{
Oyun Kuramı Muhasebe Denetiminde Kullanılabilir Mi?a
}

\author{
Anil Gacar ${ }^{b, c}$
}

\section{Özet}

Oyun kuramı, ekonomik karar alıcıların faydasının yalnızca kendi davranışlarına değil; başkalarının da davranışlarına bağlı olduğunu ortaya koyan bir teori olarak değerlendirilebilir. Oyun kuramı, özellikle istatistik, biyoloji, mühendislik, bilgisayar bilimleri ve birçok teknik alanda kullanılabilen bir yaklaşımdır. Ancak oyun kuramı konusundaki gelişmeler, bu kuramın başta ekonomi (iktisat) olmak üzere, işletmecilik fonksiyonları (halka ilişkiler, insan kaynakları, finans, muhasebe vb.) gibi sosyal bilimler alanında kullanımını olanaklı hale getirmektedir. Bu çalışmada, oyun kuramının muhasebe alanında kullanılabilirliği konusuna değinilmektedir. Muhasebe ile birlikte karar alıcılara bilgi sunulmakta olup oyun kuramı, karar verme süreçlerinde başvurulabilecek bir kavram olarak ortaya çıkmaktadır. Bu anlamda, muhasebe konuları içerisinde değerlendirilebilecek kâr yönetimi, maliyet dağıtımı, bağımsız denetim ve vekalet kuramı gibi konularda oyun kuramı uygulamalarının yer veren akademik çalışmaların olduğu görülmektedir. Çalışmada, oyun kuramının muhasebe denetiminde kullanımına yönelik bir senaryo analizi yardımıyla oyun kuramının muhasebe alanında da kullanılabileceği görüşü ortaya konmaya çalışılmaktadır.
Anahtar Kelimeler

Oyun Kuramı

Karar Alma

Denetim

\section{Makale Hakkında}

Geliş Tarihi: 28.06.2021

Kabul Tarihi: 15.12.2021

Doi: 10.18026/cbayarsos.958450

\section{Can Game Theory be Used in Auditing?}

\begin{abstract}
Game theory can be thought of as a theory that shows that the benefit of economic decision-makers depends not only on their own behavior, but also on the behavior of others. Game theory is an approach that can be used especially in statistics, biology, engineering, computer science, and many technical fields. But developments in game theory have led to the fact that this theory is mainly economics, business functions (public relations, human resources, finance, accounting, etc.) makes it possible to use it in the field of Social Sciences. In this study, the use of game theory in the field of accounting is addressed. Information is presented to decision-makers, and game theory emerges as a concept that can be applied in decision-making processes in accounting, In this sense, it is seen that there are academic studies that include game theory applications on issues such as profit management, cost distribution, independent audit and power of attorney theory that can be evaluated in accounting issues. In the study, it was attempted to put forward the view that game theory can also be used in the field of accounting with the help of scenario analysis for the use of Game Theory in the accounting field.
\end{abstract}

Keywords

Game Theory

Decision Making

Denetim

\section{About Article}

Received: 28.06 .2021

Accepted: 15.12 .2021

Doi: 10.18026/cbayarsos.958450

\footnotetext{
a Bu çalışma, 12-13 Mart 2021 tarihleri arasında düzenlenen 3. Uluslararası İzmir İktisat Kongresi'nde özet bildiri olarak sunulmuştur.

b İletişim yazarı: anil.gacar@cbu.edu.tr

c Doç. Dr., Manisa Celal Bayar Üniversitesi, İktisadi ve İdari Bilimler Fakültesi, İşletme Bölümü, ORCID: 0000-0002-4571-3886
} 


\section{Giriş}

Oyun kuramı, 1990'lı yıllardan itibaren Amerika Birleşik Devletleri'nde yaygın bir biçimde kullanılmaya başlanmıştır. Oyun kuramı özellikle, ekonomi (iktisat) bilimi açısından geniş bir kullanım alanına sahiptir. Bu kavram, 2001 yılı yapımı olan "Akıl Oyunları" filminin Türkiye'de de gösterime girmesiyle ilgi çekmeye başlamıştır (Sancak, 2008: 1). Oyun kuramı, iki veya daha fazla oyuncu arasındaki etkileşimi modelleyen ve rasyonel bireyler arasında belirsizlik ve asimetrik bilgi ile nedeniyle oluşan bir çatışmanın sonucunu tahmin eden bir yaklaşım olarak ifade edilebilir (Priantinah ve Taman, https://studylib.net, 24.01.2021).

Denetim, muhasebe süreci sonunda hazırlanan finansal tabloların genel kabul görmüş muhasebe ilkelerine uygunluğu konusunda makul bir güvence sağlayan bir faaliyettir. Bununla birlikte finansal tablolarda yer alan değerlerin gerçeğe uygun olmaması, hatalı ya da hileli işlem olmak üzere iki farklı şekilde ortaya çıabilmektedir. Hatalı işlemin hileli işlemden farkı, hatalı işlemde kasıt unsurunun olmamasıdır. Başka bir deyişle denetim firmasının finansal tablolardaki değerleri bilerek olduğundan farklı göstermesi hileli; verilerin toplanması ya da işlenmesindeki yanlış yorumlamalar da hatalı işlem olarak değerlendirilebilir. Hem hatalı hem de hileli işlemlerin önlenmesi gerekirken kaçınılması gereken en önemli unsurun hileli finansal raporlama olduğu kabul edilebilir (Anastasopoulos ve Asteriou, 2014: 51).

Denetçiler, özellikle de iç denetçiler bir işletmede üst, orta ve alt düzey çalışanların tümüyle iletişim halinde olmaktadır. Denetçilerin işletmedeki tüm çalışanlarla olan ilişki her zaman iyi olmayabilir. Bu nedenle, kişilerarası davranışların daha iyi anlaşılması, görünür çatışmaların azaltılmasında çok yardımcı olacaktır. Aslında, denetçi ve denetlenen işletmenin birbirlerinin eylemlerini algılama ve bunlara cevap verme şekli, denetim stratejisinin geliştirilmesi açısından oldukça önemlidir. Oyun kuramı, stratejik planlamayı denetime dahil edecek bir yaklaşım olarak kabul edilmektedir (Chau, 1996: 21).

$\mathrm{Bu}$ çalışmada ilk olarak oyun kuramı kavramı, oyun kuramının tarihsel gelişimi ve kullanıldığı alanları hakkında bilgiler sunulmaktadır. Oyun kuramının muhasebe denetimi alanında kullanımına yönelik literatür araştırmasının ardından bu alanda yer alan bir örnek olaya yer verilmektedir.

\section{Oyun Kuramı}

Belirsizlik koşullarında karar vermek ve buna bağlı olarak uzun vadeli (stratejik) kararlar almak, farklı bilim alanındaki bilim insanlarının ilgisini çekmiş ve dolayısıyla yapılan akademik çalışmalar, oyun kuramının gelişmesine katkı sağlamıştır (Gächter, 2004: 486). Bu konuda yapılan çalışmalar, matematikçiler tarafından başlatılmış olmakla birlikte şans ve şans oyunlarında kazanma olasılıklarının belirlenmesine dayanmaktadır. Matematikçiler tarafından başlatılan bu çalışmalar, son dönemlerde ekonomi, biyoloji, siyaset bilimi, sosyal bilimler, yapay zekâ ve makine öğrenmesi gibi birçok alanda sürdürülmektedir (Genç ve Kadah, 2018: 422). Dolayısıyla, oyun kuramı bağlamında birçok alanda matematiksel modellemelerin kullanıldı̆̆ 1 kabul edilebilir.

Oyun kuramı, birbiriyle etkileşimli oyuncular tarafından alınan stratejik kararları analiz etmek ve buradaki davranışları modellemek için kullanılan matematiksel bir yaklaşım olarak tanımlanabilir (Camerer, 2003). Burada bahsedilen oyun kavramı, işbirliği ve kurallara uygunluk (adalet) kavramları ile ilgilidir (Thaler, 2015). Oyun kuramının temeli, oyuncuların kendi çıkarlarını düşünmek suretiyle aldıkları kararın olumlu ya da olumsuz sonuçlarını 
matematiksel modellerle ortaya konulmasına yöneliktir. Bu bağlamda taraflar, aldıkları her bir kararda, diğer oyuncunun kararını da göz önünde bulundurarak bir strateji izlemektedir Mandelbrot, 2002).

Oyun kuramı, iki veya daha fazla kişi / kurum (oyuncular) arasında birinin hareketinin sonucunun, yalnızca kendi hareketine değil, diğer oyuncuların da hareketlerine bağlı olduğu durumları analiz etmek için kullanılan bir teknik olarak ifade edilebilir (Carmichael, 2005: 3). Oyuncuların aldıkları kararlarının birbirine bağımlı olmasına stratejik bağımlılık; bu tür durumlara da stratejik oyun ya da yalnızca oyun denilmektedir (Yalçıntaş, 2015: 250). Oyun kuramı, en az iki oyuncu arasındaki karar verme sürecine ilgili olarak rekabetçi karşılıklı bağımlılık durumlarını karakterize eden unsurların incelenmesiyle ilgilenmektedir (www.elsyn.gr, 22.05.2021).

Oyun kuramının bilimsel bir disiplin olarak ortaya çıkmasının 17. Yüzyılda olasılık çalışmalarına dayandığı kabul edilebilir (Hykšová 2004). Oyun mantığıyla düşünme biçiminin sosyal bilimler alanındaki ekonomi bilimine yansıması ise 19. yüzyılda yapılan çalışmalarla başlamıştır (Arrow, 2003). Oyun kuramı, sosyal bilimler açısından geliştirilmiş matematiksel modelleme tekniğidir (Giocoli, 2003). Bu bağlamda, insan ve toplumu anlamaya ve anlamlandırmaya çalışan bir dalı olarak sosyal bilimlerin, oyun kuramı gibi matematiksel modellerin kullanıldığı bir yaklaşım ile sürekli değişim içerisinde olduğu kabul edilebilir.

\section{Oyun Kuramının Unsurları}

Oyun kuramı ile ilgili ilk çalışmaların 18. yy. başlarında Fransız matematikçiler Antoine Cournot ve Joseph Bertrand tarafından yapıldığı; ancak konu ile ilgili gelişmelerin 20. yy. ortalarında görülmeye başlandığı ifade edilebilir. Bu gelişmeler, 1928'de John von Neumann'ın çalışması ve 1944'te Oskar Morgenstern'in “Oyun Kuramı ve Ekonomik Davranışlar" adlı çalışmaya ortaya konulmaktadır. Bununla birlikte John Nash, Reinheld Sten ve John Harsanyi isimli bilim insanları tarafından oyun kuramına yönelik çalışmalar da oyun kuramiyla ilgilidir. (www.elsyn.gr, 22.05.2021).

Oyun kuramıyla ilgili olarak üç unsur bulunmaktadır. Bu unsurlar, oyuncular, stratejiler ve ödemeler olarak belirtilebilir (Keskin, 2009: 7). Bu temel unsurlara yönelik açıklamalar şöyledir:

\section{Oyucular}

Bir oyuncu, herhangi bir oyun içerisinde çeşitli stratejiler arasından seçim yapmak suretiyle faydasını en fazla elde edecek şekilde karar alan birey olarak tanımlanabilir. Bir oyuncunun kararı diğer oyuncuyu etkileyeceği için burada stratejik karar alma durumundadırlar (Kaymakçı, 2003: 10). Oyuncular birey olabileceği gibi firma, ülke, kurum, ordu vb. olabilir. Oyun kuraminda oyuncuların sayısının sinırlı (en az iki) veya sinırsız sayıda olması gerekmektedir. Bununla birlikte, oyundaki tüm oyuncuların kendi çıkarlarını en üst düzeye çıkaracak ölçüde akılcı (rasyonel) olması gerektiği kabul edilmektedir (Keskin, 2009: 7).

\section{Stratejiler}

Strateji, bir oyun boyunca ortaya çıkabilecek tüm olaylar için oyuncuların kararlarını içeren bir sistem olarak tanımlanabilir (Altan, 1998: 6). Morris (1994)'e göre stratejinin üç koşulu bulunmaktadır. Bunlar, tamlık, kesinlik ve alternatif seçimlerden oluşmasıdır. Strateji kavramı, saf ve karma olmak üzere iki grupta incelenebilir. Bir oyuncunun net bir şekilde 
belirleyebileceği stratejiye saf strateji adı verilirken; saf stratejilerin belirli olasılıklarla birleştirilmiş haline de karma strateji adı verilmektedir (Varian, 1993: 473).

Örneğin, seyahat etmek isteyen bir birey, otobüs ya da otomobille arasında tercih yapmak istemektedir. Oyuncu yazı-tura atarak 0.5 olasılıkla otobüs; 0.5 olasılıkla da otomobil seçeneklerinden birisini seçebilir. Bu durum, oyuncu açısından saf stratejidir. Saf strateji oyuncunun kazancını en büyükleyecek tek bir stratejiye bağlı kalmasıdır. Yani oynadığı tüm oyunlarda yüzde yüz otomobil seçmesi, karma strateji oyunların \%50'sinde otobüsü, \%50'sinde otomobili seçmek şeklinde stratejileri arasında dağılımlı bir olasılık kullanmasıdır. (Kaymakçı, 2004: 14).

\section{Ödemeler veya Kazanç}

Herhangi bir oyunun sonucu, oyundaki oyuncuların hangi stratejileri seçtiğine bağlı olarak değişebilmektedir. Bir oyundaki her bir oyuncu, kendi stratejilerini belli kurallar çerçevesinde seçtikleri anda, oyunun sonunda bu stratejilerin oyunculara yüklediği kazanç ya da kayıp bulunmaktadır. Buradaki kayıp ya da kazancın sayısal olarak ifade edilmesi gerekmektedir. Ancak bazı durumlarda; mutlu olmak, tatmin edilmek, saygınlık kazanmak ya da bunların tersi gibi nitel (kalitatif, öznel) bazlı ödemeler de söz konusu olabilir. Bu şekilde kalitatif ödemeli oyunlarla olabilmek için gerekli olan temel esas, bu ödemeleri nicel (sayısal) hale getirmektir. Nitel bazlı ödemeler, nicel olan ödemeler ile değiştirilmesi sürekli bir şekilde yapılabilir (Morris, 1994). Kısaca, nitel bazlı ödemelerin nicel olanlarla değişimi sürekli mümkün olabilmektedir.

Diğer istatistiksel modellerden farklı olarak oyun kuramı, insanların rekabetçi bir oyun ortamındaki etkileşimlerini öngörmekte ve çeşitli koşullar altında bir dizi mantıksal strateji bulmaya çalışmaktadır. Oyun kuramı, yönetim bilimi ve ekonomi ile yönetim ve maliyet muhasebesi alanlarında kullanım alanı bulabilmektedir (Chau, 2002: 21).

\section{Literatür Özeti}

İşletmeler, sahip oldukları finansal bilgiler, finansal tablolar aracılığıyla birçok çıkar grubunun (kredi veren kuruluşlar, yatırımcı, yönetici, devlet, sivil toplum kuruluşları, çalışanlar vb.) kullanımına sunmaktadır. Çıkar grupları da elde ettikleri bu finansal bilgiler ile ekonomik kararlar almaktadır. Ancak, karar alıcıların isabetli karar vermelerinin temel koşulu, işletmelerin finansal tabloları aracılığıyla yayınladıkları bilgilerin gerçek ve güvenilir olmasına bağlıdır. İşletmelerin finansal tablolarının gerçek verilere dayalı olup olmadığı; başka bir anlatımla genel kabul görmüş muhasebe ilkelerine göre düzenlenip düzenlenmediği konusunda görüş bildirecek olan unsur, bağımsız denetimdir.

Bağımsız denetim faaliyetini yerine getirecek olan denetçi işletme, denetlenen (müşteri) işletmeyle denetim sözleşmesi hazırlamaktadır. Hazırlanan bu denetim sözleşmesinde denetim faaliyetinin süresi ve bu hizmet karşılığındaki ücret belirlemektedir. Sözleşme yapılmasının ardından denetim faaliyeti başlamakta ve bunun ardından müşteri işletmenin finansal tablolarının Uluslararası Muhasebe Standartlarına ve yasal düzenlemelere uygun olup olmadığı hakkında görüşü beyan edilmektedir. Denetçi işletme, elde ettikleri bulgulara göre olumlu, olumsuz, şartlı görüş bildirebilmekte ya da görüş bildirmekten kaçınma yoluna gidebilmektedir (Acar vd, 2013: 2). 
Denetim faaliyeti sonucunda verilen görüş, her zaman doğru olmayabilir. Denetim işletmesinin yanlış görüş bildirme olasılığına denetim riski adı verilmektedir. Denetim riskinin yüksek olduğu durumlarda denetimin maliyeti yüksek; riskin düşük olduğu durumlarda maliyet düşüktür. Kısaca, denetim riski yüksek olan işletmeler, denetim işletmesine daha yüksek ücret ödeyebilmektedir.

Oyun kuramı denetim alanında, denetçilerin ve yöneticilerin diğer oyuncular tarafından alınan kararları dikkate aldıktan sonra kendi kararlarını nasıl verdiklerini açıklamak ve analiz etmek için kullanılabilir (www.elsyn.gr, 22.05.2021). Denetim riski, hiçbir zaman sıfırlanamaz. Oyun teorisi ve muhasebe arasındaki ilişki bağlamında literatürde, sıfırlanamayacak olan risk karşısında, denetim maliyetlerinin en aza indirilmesiyle ilgili olarak denetleyen ve müşteri işletme arasındaki ilişkinin belirlenmesine yönelik çalışmalar yer almaktadır (Acar vd. 2013: 2). Aşağıda, muhasebe denetimiyle ilgili oyun teorisi kapsamında yer alan çalışmalar özetlenmeye çalışılmıştır:

Dassiou ve Glycopantis (2019), denetim davranışı ile ilgili bir çok ampirik çalışmanın denetçinin ünü ve büyüklüğüne bağlı olduğunu belirtmektedir. Çalışmada kurulan modele göre bir denetçinin denetim faaliyeti sırasında karşılaştığı rüşvet, prim ve para cezaları içeren hile tespit oyunu bulunmaktadır. Elde edilen sonuca göre primlerin büyüklügüünden etkilenen denetçinin ünü, müşteri işletme tarafından hileli olmayan bir davranış oluşturmak için kritik bir öneme sahiptir. Bu bağlamda, kurulan modelin beklenen sonucu doğruladığ görülmektedir.

Saei vd. (2018), oyun kuramı yaklaşımını kullanarak denetçi ve yöneticilerin çıkarlarını maksimize etmede optimal stratejinin belirlenmesine yönelik bir çalışma gerçekleştirmişlerdir. Burada yöneticinin çıarı kar yönetimi; denetçinin çıkarı ise denetim faaliyetinin kalitesidir. Çalışmada 116 işletme üzerine bir anket gerçekleştirilmiş olup çalışma bulguları, yüksek denetim kalitesi ve kar yönetimi stratejisinde "Nash Dengesi" olarak bilinen oyun kuramının varlığını ortaya koymaktadır.

Abdelaziz vd. (2016) çalışmalarında genel olarak, muhasebe çalışmalarının muhasebe verilerinin istatistiksel özelliklerini ve bunların karar verme üzerindeki etkilerini analiz etmeye odaklandığını belirtmektedir. Buna göre çalışmalarında, farklı karar vericilerin stratejik etkileşimini dikkate alan alternatif bir yaklaşım, muhasebe verilerinin "oyun-teorik görünümü" kullanılarak geliştirilmiştir. Yazarlar, oyun teorisini açıklayan ve bu teoriyi denetim alanında uygulayan ana çalışmaları gözden geçiren temel bir ortam sunmaktadır. $\mathrm{Bu}$ çalışma, uzman olmayan okuyucunun denetim sürecinde stratejik etkileşimin önemini anlamasına yardımcı olabilecek nitelikte değerlendirilebilir.

Anastasopoulos ve Asteriou (2014), klasik oyun kuramı formülasyonlarının (oyuncuların dengeye nasıl ulaştığı, ulaşın dengenin sabit olup olmaması ve denetçinin görev süresinin denetim kalitesi üzerindeki uzun vadeli davranışının ne olduğu) başarısız olması nedeniyle, denetim teorisi üzerine alternatif bir formülasyon ortaya koyan bir çalışma gerçekleştirmiştir.

Hatherly vd. (2006), denetimi, düzenleyici bir makam tarafından uygulanan bir ceza rejimi çerçevesinde denetçi ve denetlenen kurum tarafından oynanan ortak bir oyun olarak modellemektedir. Çalışmada, düzenleyici tarafından belirlenen cezalar ile denetçi ve denetlenen kurumun ortaklaşa kararlaştırılan stratejisi arasındaki ilişkiyi araştırmakta ve ceza rejiminin, yüksek çaba seviyeleri gibi belirli bir stratejik sonucu teşvik etmek için nasıl kullanılabileceği tartışılmaktadır. 
Wilks and Zimbelman (2004), finansal raporlamada hilenin bulunması ve önlenmesiyle ilgili olarak denetçilere yardımcı olabilecek bir çalışma gerçekleştirmişlerdir. Stratejik hile ayarına odaklanan bu çalışma, denetçilerin stratejik akıl yürütmesini kolaylaştıracak düzenlemeler önermektedir. Bununla birlikte çalışmada, hile riskinin değerlendirilmesi, denetim planlaması ve denetim planı uygulaması olmak üzere üç kritik denetim görevi önerilmektedir.

Çavuşoğlu ve Raghunatan (2004), stratejik kullanıcılarla karşı karşıya kalındığında denetim yazılımı yapılandırma sorununu tespit etmede karar verme ve oyun kuramı yaklaşımlarını karşılaştırmıştır. Çalışmada, denetim yazılımı yapılandırma sorununu tespit etmede oyun kuramının karar verme yaklaşımına göre daha başarılı sonuçlar verdiği ortaya konmuştur. Aynı zamanda çalışmada, karar teorisi ve oyun teorisi altındaki yapılandırmalar yeterince yakınsa, firmalar aynı anda hareket eden bir oyunda oyun teorisi yaklaşımına kıyasla karar teorisi yaklaşımı altında aynı veya daha düşük maliyete maruz kaldığı belirtilmektedir.

Coate vd. (2004), finansal tabloların "korkak tavuk" ya da "refah oyunu"ndan biri ile analiz edildiğinde; refah oyunun tercih edilmesi gerektiğini belirtmektedir. Korkak tavuk oyunu stratejisi, denetçinin herhangi bir ayrıntılı inceleme yapmadan görüş bildirmesi; denetlenen işletme açısından ise hileye başvurmamak şeklinde ifade edilmektedir. Ohta (2002), denetim risklerini oyun teorisi ile azaltmaya çalışan bir çalışma gerçekleştirmiştir.

Migdalas (2002), 1980'li ylllardan itibaren oyun kuramının ekonomi, endüstriyel organizasyon, işletme stratejisi, muhasebe, finans ve pazarlama alanlarındaki sorunlara yönelik bir çözüm olarak uygulanabildiğini belirtmektedir. Çalışmada, oyun kuramının finans ve yönetim muhasebesi alanlarda nasıl kullanılabileceğine yönelik bilgiler sunulmaktadır.

Chau (1996), oyun kuramının denetçilere olan faydalarını analiz ettiği çalışmasında, denetime özgü çelişkili davranışlar bulunduğunu; oyun kuramının da denetimdeki bu davranışları tanımlamak için elverişli olduğunu belirtmektedir. Çünkü denetim firması, müşteri işletmeden bilgi almaktadır. Sonuç olarak çalışmada, finansal bilginin güvenilirliğini sorgulamda denetçinin daha fazla ihtiyaç duyduğu belirtilmektedir.

Matsumara ve Tucker (1992), yönetici ve denetçi arasındaki stratejik etkileşime ve özellikle yöneticinin bir sahtekarlık yapma (ya da yapmama) ikilemine yönelik bir çalışma gerçekleştirmişlerdir. Bu bağlamda, denetim standartlarının gerekliliği, iç kontrol yapısının kalitesi, denetim ücreti gibi değişkenlerin hilelerin tespit edilmesindeki etkinliğini araştırma konusu yapmışlardır.

Fellingham ve Newman (1985), denetlenen işletmenin iç kontrol sisteminde yüksek veya düşük çaba kullanma arasında karar verdiği ve denetçinin de iç kontrolü araştırmak için yüksek veya düşük çaba kullanma arasında karar verdiği bir örneğe odaklanmaktadır. Kanodia (2014), denetçinin işe alımı ve ters seçim varlığında denetim faaliyetinin ücreti konusundaki literatür üzerine bir çalışma gerçekleştirmiştir.

LeMarie (1984), sigorta şirketlerindeki maliyet dağıtımında oyun kuramının kullanımına yönelik bir uygulamayı içeren çalışmasında, sigorta şirketleri açısından maliyet dağıtımının, muhasebenin en zor konularından biri olduğunu belirtmektedir. Yazar bu çalışmada, sigorta şirketlerinde maliyet dağıtımı sorununu çözmek için oyun kuramından yararlanarak dört muhasebe yöntemini incelemiştir. Çalışma sonucunda, özellikleri dolayısıyla oransal esaslama yönteminin kullanılması önerilmektedir. 
Çalışmada, muhasebe denetimi ve oyun teorisi ilişkisinin uygulamalı olarak incelenmesi amaçlanmaktadır. Bu amaçla, hipotetik bir denetim faaliyeti üzerinden, denetleyen ve denetlenen işletmelerin stratejik kararları, oyun kuramı bağlamında senaryolalaştırılarak incelenmektedir. Senaryo, "dikkatlerin nedensel prosesler ve karar noktaları üzerine odaklanması amacı ile meydana getirilen ve birbirini izleyen kuramsal olaylar" şeklinde tanımlanabilir (Altuğ, 2002: 182). Senaryo analizi, geleceği şekillendiren dinamiklerin belirlenmesi ve gruplandırılması yoluyla gelecekteki olası seçeneklerin ve bu seçeneklere hangi yollarla ulaşılabileceğinin belirlenmesidir. Senaryolar geleceği tahmin etmenin ötesinde, gelecekte değişimin sürükleyici güçlerinin, farklı olasılıklar kapsamında nelere yol açabileceğini göstermektedir (Kalkınma Bakanlığı, 2018: 2). Senaryo analizi, stratejik yönetim araçlarından biri olup gelecekte neler olabileceğinin öngörülmesinde kullanılabilmektedir (Aktan, 1999). Senaryo analizinin oluşturulmasında Kukreja (2015)'nın yaptığı çalışmadan yararlanılmıştır.

\section{Senaryo}

Aşağıdaki tabloda, hesap denetimine ilişkin bir oyun teorisi senaryolaştırılmıştır:

Tablo 1: Hesap Denetimi Oyununda Kazanç Değerleri

\begin{tabular}{|c|c|lc|lr|}
\hline & \multicolumn{3}{c|}{ Muhasebeci } \\
\hline \multicolumn{2}{|c|}{ Denetim Oyunu } & \multicolumn{2}{c|}{ Hile Var } & -9 & \multicolumn{2}{c|}{ Hile Yok } \\
\hline \multirow{3}{*}{$\begin{array}{c}\text { Denetleyen } \\
\text { İşletme }\end{array}$} & $\begin{array}{c}\text { Denetimin } \\
\text { Varlığı }\end{array}$ & 9 & & 3 & 5 \\
\cline { 2 - 6 } & $\begin{array}{c}\text { Denetimin } \\
\text { Yokluğu }\end{array}$ & -9 & 9 & & \\
\hline
\end{tabular}

Yukarıdaki tabloda;

- İki oyuncu: Denetleyen işletme ve muhasebeci

- Denetleyen işletme: Bir denetim faaliyeti gerçekleştirebilir ya da gerçekleştiremez.

- Muhasebeci: Hesaplarda hile yapabilir ya da yapamaz.

- Kazanç: Her bir oyuncunun faydasını yansıtan tamsayıları göstermektedir. Sol altta yer alan tamsayılar denetleyen işletme için sağ üstte yer alan tamsayılar da hesap işlemini gerçekleştiren muhasebecinin faydasını ifade etmektedir.

Tablo 1'de kazanç değerleri toplamının her zaman sıfır olmadı̆̆ görülmektedir. Kazanç toplamlarının her zaman sıfır olması beklenmemekle birlikte birlikte; gerçeğin modellenmesi açısından sıfır toplamlı oyunun varlı̆̆ı oyuncuların kazançlarına bağlı olarak değişebilmektedir. Şu şekilde bir örnek vermek gerekirse; denetim faaliyetini gerçekleştiren işletme, denetlediği işletmeyle ilgili bir hile tespit ederse bu yöndeki çabaları ödendiği için bir kazanç elde etmektedir. Muhasebe hilesinin tespitine bağlı olarak muhasebeci de yakalanarak bu durumdan aynı oranda bir kazanç elde edebilmektedir (işten çıkarılma, vergi cezasına maruz kalma vb.). Tablo 1'de her iki oyuncunun (denetleyen ve denetlenen) kârı ençoklayan durumun denetimin ve hilenin yokluğu $(8,5)$ olduğunu ifade etmek mümkündür. Bu durumda her iki oyuncu da hiçbir çaba ve maliyet üstlenmeden çıarlarını 
ençoklayabilmektedir. Bunun ardından kârı ençoklayan diğer durumun ise denetimin varlığı durumunda hilenin olmaması olduğu $(3,5)$ olduğu belirtilebilir.

Benzer şekilde, denetim yapan işletmenin denetim faaliyetini yapmaması ya da eksik yapması durumunda denetleyen işleme bir kazanç elde edecektir; çünkü denetçi daha az faaliyette bulunduğu için tasarruf etmiş̧tir. Aynı zamanda muhasebecinin de hileli işlem yapmaması; başka bir deyişle işini yapması durumunda muhasebeci de bu durumdan yüksek kazanç elde edebilecektir. Kısaca, yüksek denetim faaliyeti-hile tespitinin varlığ1 ya da düşük denetim faaliyeti-hile tespitinin yokluğu gibi iki farklı durum oyun teorisi kapsamında değerlendirilebilmektedir.

Senaryoya göre yalnızca bir denetleyen işletme ve buna karşılık incelenmesi gereken 100 hesap bulunmaktadır. Bu durumda, öncelikle hangi hesapların kontrol edilmesi gerektiği oldukça önemli bir konudur. Denetleyen işletme ilk aşamada, rastgele örneklem seçimiyle hangi hesabın öncelikli olarak kontrol edileceğine karar verebilir. Rastgele örneklem seçimiyle hangi hesapların öncelikli olarak kontrol edileceğinin belirlenmesi oldukça adil bir durumdur. Buna karşılık, tamamen rastgele örneklem seçimi yanında hesapların seçiminde daha farklı yöntemlerin seçilmesi; denetçinin elde edeceği denetim ücretinin artmasına; başka bir deyişle kazancının artmasına neden olabilecektir. Ancak, denetleyen işletme ve muhasebecinin her ikisinin de amacı faydalarını ençoklamaktır; bu bağlamda bu tip kararların (hangi hesabın öncelikli kontrol edileceği gibi) birlikte verilmesi gerekmektedir.

Bununla birlikte birçok olayda muhasebeciler, denetçilerin eylemlerine ilişkin aynı gözlem geçmişine sahiptir. Daha sonra muhasebeciler, eylemlerinin ne olması gerektiğine karar vermek için aynı gözlem geçmişine sahip olma durumunu kullanabilmektedir. Bu, eşzamanlı olmayan bir hareket oyunudur. Muhasebeciler, denetçinin eylemlerini gözlemleyebilir ve denetçilerin eylemlerine göre hile yapıp yapmamaya karar verebilir. Muhasebeciler, denetçilerin eylemlerine ilişkin tarihsel veriler yardımıyla, denetçilerin rastgele tahmin seçimine yönelik bir olasılık tahmininde bulunabilirler. Ancak, muhasebecinin hile yapma durumuyla ilgili olarak denetim yapan işletmenin hangi hesapları öncelikli olarak kontrol edeceği kesin olarak bilinemeyeceği için hile yapılmaması konusunda caydırıcılık bulunabilmektedir. Hile yapılmaması için Stackelberg dengesi hesaplanarak en uygun rastgele/karma strateji belirlenebilir. Stackelberg modeli, herhangi bir oyunda, bir oyuncunun kararının ardından diğer oyuncunun buna göre karar vermesi olarak ifade edilebilir (Valeriu, 2018). Dolayısıyla, muhasebeci hesaplarda hile yapıp yapmamaya, denetleyen işletmenin eylemlerine göre karar verebilecektir.

Oyun kuramı modeli, eylemlerinizi görebilen ve sonra kendi eylemlerine karar veren uyarlanabilir bir rakibin (en az ikinci oyuncunun varlı̆̆ı) olduğu her durumda kullanabilir. Buradaki önemli nokta, zaman zaman bazı kaynak kısıtlamalarına gidilmesinin gerekliliğidir. Kısacası, oyun kuramında hiçbir şey tam olarak kontrol altına alınamaz. Kazancın en üst noktaya çıkarılabilmesi için oyun kuramı şu denetim ya da kontroller için kullanilabilmektedir: Bunlar,

- Hastane kayitları,

- Park sayaçları,

- Vergi denetimleri, 
- Sınav sorularının belirlenmesi (tüm sınav soruları yayımlanmış olsa bile sınavda hangi soruların geleceği kesin olarak bilinememektedir)

- Ödevlerin notlandırılması,

- İşletmeler için yüksek düzeyde stratejiler belirlenmesi ve

- Altyapının olası saldırılardan korunması güvenlik kaynaklarının nasıl dağıtılacağının planlanabilmesi şeklinde sıralanabilir.

\section{Sonuç ve Öneriler}

Oyun kuramı, karar verme tekniklerinden biri olarak son dönemde birçok alanda kullanılmaktadır. Bu alanların biri de muhasebe denetimidir. Muhasebe denetiminde amaç, denetlenen işletmenin finansal tablolarının genel kabul görmüş muhasebe ilkelerine hazırlanıp hazırlanmadığının belirlenmesidir. Yapılan denetim faaliyeti sonucunda, denetleyen işletme tarafından finansal tablolar hakkında olumlu, olumsuz ya da şartlı görüş bildirilebileceği gibi görüş bildirmekten kaçınma durumu da söz konusu olabilmektedir. Finansal karar alıcılar, denetim sonucu açıklanan görüşe güvenmek istemektedir.

Denetim faaliyeti, denetleyen ve denetlenen işletme arasında yapılan bir sözleşme ile başlamaktadır. Yapılan sözleşmede, denetleyen işletmenin alacağı ücret ve denetimin kapsayacağ 1 süre bilgisi yer almakta; bu anlamda bir taraf için gelir, diğer taraf için ise maliyet oluşmaktadır (Acar vd., 2013: 16). Denetlenen işletme denetim maliyetini düşürmek; denetleyen işletme ise bu faaliyeti süresi içinde bitirmek istemektedir.

Denetleyen işletme tarafından, doğru denetim görüşünün oluşturulamaması durumu denetim riski olarak ifade edilmektedir. Müşteri işletmeyle ilgili daha fazla denetim kanıtı toplanması yoluyla denetim riski düşürülebilmektedir. Denetim riskinin yüksek olması, denetim kanıtlarının sayısını arttırmakta; başka bir deyişle denetimde harcanan zamanı arttırabilmektedir. Bu durum da doğrudan denetim maliyetinin yükselmesine neden olacaktır. Denetleyen işletme tarafından denetimde harcanan zamanın artmaması; diğer taraftan da denetim maliyetinin yükselmemesi her iki kesim için de tercih edilen bir durumdur. Oyun kuramı yardımıyla hem denetimde harcanacak zaman; hem de denetim maliyetinin düşürülmesi yoluna gidilebilecek olup bu durum, her iki kesim açısından da en uygun ve akılcı karar olabilecektir.

Bu çalışma sonucunda, bir senaryo analizi yardımıyla muhasebe denetiminde oyun kuramının uygulanabileceği görülmektedir. Yapılan literatür çalışmasında da oyun kuramının muhasebe denetiminde uygulanabileceği ortaya konulmaktadır. Daha sonraki çalışmalarda, muhasebenin risk yönetimi, iç denetim, maliyet muhasebesi gibi alanlarında oyun kuramının uygulanabilirliğine yönelik analizlerin yapılabileceği önerilmektedir. 


\section{Kaynakça}

Abdelaziz, F. B. vd. (2016). Auditing and Game Theory: A Survey. In: Al-Shammari M., Masri H. (eds) Multiple Criteria Decision Making in Finance, Insurance and Investment. Multiple Criteria Decision Making. Springer, Cham.

Acar, D. vd. (2013). Bağımsız Denetim Maliyetinin İşbirlikçi Oyun Modeli Yaklaşımıyla Minimizasyonu. Uluslararası Yönetim İktisat ve İşletme Dergisi. 9 (18).

Aktan, C.C. (1999). 2000'li Yıllarda Yeni Yönetim Teknikleri: Stratejik Yönetim. İstanbul. Simge Ofis

Anastasopoulos, N. P; Asteriou, D. (2014). Applications of Game Theory And Evolutionary Game Theory in Auditing. International Journal of Mathematics, Game Theory, and Algebra; Hauppauge. 23(1). 51-64

Arrow, K. J. (2003). "Introductory remarks on the history of game theory." Games and Economic Behavior 45 (1). 15-18.

Altan, S. (1998). Oyun Teorisi. İstanbul Üniversitesi Sosyal Bilimler Enstitüsü Basılmamış Yüksek Lisans Tezi. İstanbul

Altuğ, B. (2002). Stratejik Planlamada Senaryo Teknikleri ve Yeni Yaklaşımlar. İstanbul Ticaret Üniversitesi Dergisi. 181-194

Camerer, C. (2003). Behavioral game theory. Princeton, NJ: Princeton University Press.

Carmichael, F. 2005. A Guide to Game Theory. Essex: Pearson Education Limited.

Chau, C. T. (1996). Game theory and strategic auditing: Part I-Introduction. Managerial Auditing Journal, 11, 21-25.

Coate, C. J. vd. (2002). Financial statement audits, a game of chicken. Journal Of Business Ethics, $41,1-11$.

Çavuşoğlu, H. ve Raghunathan, D. (2004). Configuration of Detection Software: A Comparison of Decision and Game Theory Approaches. Decision Analysis 1(3):131-148

Dassiou, X. ve Glycopantis, D. (2019). The importance of reputation in the auditing of companies: A game theory analysis. 19(1). London, UK: City, University of London.

Fellingham, J.-C., \& Newman, D.-P. (1985). Strategic considerations in auditing. The Accounting Review, 60, 634-650.

Gächter, S. (2004). Behavioral game theory. Blackwell handbook of judgment and decision making, 485-503

Genç, S. Y. ve Kadah, H. (2018). Oyun Kuramı ve Nash'in Denge Stratejisi. Iğdır Üniversitesi Sosyal Bilimler Dergisi. 14, 419-440

Giocoli, N. (2003). Fixing the point: the contribution of early game theory to the toolbox of modern economics, Journal of Economic Methodology 10 (1), 1-39.

Hatherly, D. vd. (2006). Game Theory and the Auditor's Penalty Regime. Journal of Business Finance \& Accounting 23(1):29 - 45

Hykšová, M. (2004). Several Milestones in the History of Game Theory, VII. Österreichisches Symposion zur Geschichte der Mathematik, Wien 
Kanodia, C. (2014). Game theory models in accounting. In K. Chatterjee \& W. Samuelson (Eds.), Game theory and business applications (International series in operations research \& management science, Vol. 194). New York: Springer

Kaymakçı, Ö. B. (2003). Oyun Kuramı ve Piyasalarda Denge Analizi. İstanbul Üniversitesi Sosyal Bilimler Enstitüsü Yayımlanmamış Yüksek Lisans Tezi. İstanbul

Keskin, H.İ. (2009). Oyun Kuramının Ekonomide Uygulanması. Çukurova Üniversitesi Sosyal Bilimler Enstitüsü Yayımlanmamış Yüksek Lisans Tezi. Adana

Kukreja, N. (2015). Is there any application of "Game Theory" in accounting? https://www.quora.com/Is-there-any-application-of-Game-Theory-in-accounting (20.11.2020)

LeMarie, J. (1984). An Application of the Game Theory: Cost Allocation. ASTIN Bulletin, 14(1), 6181

Mandelbrot, J. (2002). Oyun Kuramı Türkiye'ye Ne Kazandırır? https://turk-internet.com/oyunkuram1-turkiye-ye-ne-kazandirir/ (24.12.2020)

Matsumara, E.M. ve Tucker, R.R. (1992). Fraud detection: A theoretical foundation. The Accounting Review, 67, 753-782.

Migdalas, A. (2002). Applications of game theory in finance and managerial accounting. Operational Research, 2(2), 209-241

Morris, Peter, (1994). Introduction to Game Theory, New York, Springer-Verlag.

Ohta, Y. (2002). The forensic-type phase: A game-theoretic analysis of fraud detection in auditing. Doctor of Philosophy. State University of New York, Buffalo U.S.A. November 22.

Priantinah, D. ve Taman, A. Application of Game Theory in Accounting, https://studylib.net/ (24.01.2021).

Saei, M.J. vd. (2018). Strategic Game Manager - Auditor: Evidence of Game Theory. Accounting and Auditing Review, 25(4), 497-518.

Sancak, Y. (2008). Borsa İşlemlerinde Oyun Kuramı Kullanımı. Yüksek Lisans Tezi, Sakarya Üniversitesi, Fen Bilimleri Enstitüsü.

Thaler, R. (2015). Misbehaving: The making of behavioral economics. New York: W. W. Norton \& Company.

T.C. Kalkınma Bakanlığı (2018). Stratejik Planlama için Analiz ve Yöntemler Rehberi. http://www.sp.gov.tr/upload/xSpKutuphane/files/I0zj6+Stratejik_Planlama_Icin_Analiz_ve_Y ontemler_Rehberi.pdf (Erişim Tarihi: 22.05.2021)

Valeriu, U. (2018). Pareto-Nash-Stackelberg Game and Control Theory: Intelligent Paradigms and Applications. Springer

Varian, H. R. (1993). Intermediate Microeconomics: A Modern Approach. Third Edition. W. W. Norton \& Company New York London.

Wilks, T. J. ve Zimbelman, M.F. (2004). Using Game Theory and Strategic Reasoning Concepts to Prevent and Detect Fraud. Accounting Horizon. 18(3). 173-184

Yalçıntaş, M. (2015). Ekonomik Karar Almada Adalet ve Oyun Kuramı. Maliye ve Finans Yazıları Dergisi. 103, 247-274

https://www.elsyn.gr/sites/default/files/Game_theory_and_audit.pdf (Erişim Tarihi: 22.05.2021) 